\title{
Prevelance of Eye Diseases in Primary School Students in Nagrota
}

\author{
Authors \\ Dr Vijayta Gupta ${ }^{1}$, Dr. Ridham Nanda ${ }^{2}$ \\ ${ }^{1,2}$ MS, Senior Resident, Dept of Ophthalmology, Acharya Shri Chander College of Medical Sciences, \\ Jammu INDIA \\ Corresponding Author \\ Ridham Nanda MS
}

Senior Resident, Dept of Ophthalmology, Acharya Shri Chander College of Medical Sciences, Jammu

Email: ridznanda@gmail.com

\section{ABSTRACT}

Aim: The study measured the prevalence of eye diseases in primary school children between 5 to 12 years of age.

Material and Methods: Cross-sectional and observational study was carried in June 2017 on students of classes 1st to 5th of Kendriya Vidhyalaya, Nagrota. A short talk on eye health was given to the children before the eye examination.

After obtaining verbal informed consent from parents and school heads, visual acuity with snellen's chart, colour vision with ishiara chart, diffuse torch light examination of anterior segment of eye and fundus examination using direct ophthalmoscope in undialated pupil in students was carried out in all available and eligible students aged 5-12 years.

Results: Out of 530 students, there were 307 (57.2\%) males and 223 (42.075\%) females. Out of 530 children, the prevalence of ocular morbidity was $17.54 \%$ (93 children). The most common causes of ocular morbidity were refractive error in $66(12.45 \%)$ children and conjunctivitis in $14(2.64 \%)$ children. Other causes of ocular morbidity were strabismus and chalazion- 3 children each $(0.56 \%$ each), color blindness, amblyobia- 2 children each (0.38\%). Stye, ptosis and corneal scar (due to ocular trauma) was seen in 1 student each (0.18\%). 87.16\% students had vision 6/6.Out of refractive errors, $33.33 \%$ students had vision $6 / 9,59.09 \%$ students had vision 6/12, 6.06\% students had vision 6/18 and 1.5\% had vision 3/60. 30.30\% students were already using spectacles.

Conclusion: The commonest cause of visual impairment in school students was refractive errors which is preventable which is treatable. Conjunctivitis was the second most common ocular disorder which is also preventable and treatable. Therefore, proper screening and evaluation of school students if done timely can help in reducing the ocular morbidity burden in the society.

Keywords: Eye disease, prevalence, school children.

\section{INTRODUCTION}

According to the World Health Organisation (WHO), about $75 \%$ of causes of blindness can be avoided through preventive or therapeutic measures.
Control of childhood blindness is main priority of the WHO through its programme "VISION 2020: the Right to Sight"1. 
About 500,000 children become blind each year worldwide, and $70 \%$ die in the first years of life due to diseases causing visual impairment2. Populationbased studies show that the prevalence of childhood blindness is higher in developing than in developed countries.

Ocular morbidities such as uncorrected refractive errors are more common in school children. These have a significant effect on their learning capability and educational potential. In India children below the age of 15 years constitute significant proportion of the population. Therefore schools are one of the best centres for effectively implementing the comprehensive health care programme. Early diagnosis and treatment of ocular disorders can significantly reduce ocular morbidity burden in community. In 1960 the Government of India constituted a school health committee which recommended medical examination of children at the time of entry into school and thereafter every 4 to 5 years. Children suffer from a variety of eye conditions from causes such as refractive errors, vitamin A deficiency, conjunctivities, squint, measles, and sickle cell diseases. Childhood eye conditions like refractive errors can be corrected to improve vision while xerophthalmia and trachoma are both preventable and treatable. Trachoma is rare nowadays. It has been reported that school-going age children (6-16 years) form $25 \%$ of the population in developing countries3. They fall within the preventable blindness age group as they are easily accessible in schools that are good forum for imparting health education to the children4.It is very essential to do perodic screening of children to improve the quality of eye-sight. 5

\section{MATERIALS AND METHODS}

Cross-sectional and observational type of study was carried in June 2017 on students of classes 1st to 5th of Kendriya Vidhyalaya, Nagrota. A total of 530 students participated in this study. A short talk on eye health was given to the children before the eye examination.

After obtaining verbal informed consent from parents and school heads, visual acuity with snellen's chart, colour vision with ishiara chart, diffuse torch light examination of anterior segment of eye and fundus examination using direct ophthalmoscope in undialated pupil in students was carried out in all available and eligible students aged 5-12 years. Uncooperative students, students absent from school during the day of examination were excluded from the study group.

Distant visual acuity (VA) was measured using the Snellen's visual acuity chart at $6 \mathrm{~m}$. Children with $\mathrm{VA}<6 / 6$ underwent a pinhole vision to differentiate refractive errors from pathological conditions. Refractive error was diagnosed when VA less than 6/6, improved on pin-hole test. Examination of the eyelid margins, conjunctiva, the cornea and anterior segment of the eye was performed under torch light. Hirschberg test and cover-uncover test were also carried out to detect strabismus. The posterior segment of the eyes of each participant was examined in a darkened room using the Welch Allyn direct ophthalmoscope in undialated pupils of the students. No drug was administered to any child. All information was recorded in the proforma especially designed for the purpose of this study.

Then data was entered in MS Excel and was analysed in percentages and proportions.

\section{RESULTS}

This study was conducted on 530 students of class 1st to 5th. Age range of the students was 5-12 years. Average age of students was- 8.14 years.

There were $307(57.2 \%)$ males and 223 (42.075\%) females. Out of 530 students, there were 307 (57.2\%) males and 223 (42.075\%) females. Among 530 children, the prevalence of ocular morbidity was $17.54 \%$ (93 children). The most common causes of ocular morbidity were refractive error in $66(12.45 \%)$ children and conjunctivitis in 14 $(2.64 \%)$ children. Other causes of ocular morbidity were strabismus and chalazion- 3 children each $(0.56 \%$ each $)$, color blindness, amblyobia- 2 children each $(0.38 \%)$. Stye, ptosis and corneal scar (due to ocular trauma) was seen in 1 student each $(0.18 \%)$. $87.16 \%$ students had vision $6 / 6$. Out of refractive errors, $33.33 \%$ students had vision $6 / 9$, 
$59.09 \%$ students had vision 6/12, 6.06\% students had vision $6 / 18$ and $1.5 \%$ had vision $3 / 60$. $30.30 \%$ students were already using spectacles.

\begin{tabular}{|l|c|c|}
\hline \%age & No. of Students & Ocular morbidity \\
\hline 12.45 & 66 & Refractive Errors \\
\hline 2.64 & 14 & Conjunctivitis \\
\hline 0.56 & 3 & Squint \\
\hline 0.57 & 3 & Chalazion \\
\hline 0.38 & 2 & Colour blindness \\
\hline 0.38 & 2 & Amblyopia \\
\hline 0.18 & 1 & Ptosis \\
\hline 0.18 & 1 & Stye \\
\hline 0.18 & 1 & Corneal scar \\
\hline 100 & 93 & Total \\
\hline
\end{tabular}

\section{DISSCUSSION}

School screening is important for public and educational health, as many children reach school age without having undergone any ocular examination. Around 15\% of first-grade children have some visual disorders, and only $20 \%$ undergo medical follow-up6. Every child ideally should be examined by an ophthalmologist before starting school and should undergo preventive eye examination in the first year of life. In recent years there is increasing awareness of the need for such preventive measures, with programmes specially focussed on newborn and school children being used to screen children with eye disorders. Childhood eye disorders can contribute to the burden of blindness in a society. In this study the prevalence of ocular morbidities was found to be $17.54 \%$. The commonest cause of ocular morbidity in the present study was refractive errors with a prevalence of $12.45 \%$. Refractive error is one of the most common causes of visual impairment around the world and the second leading cause of treatable blindness7. Out of 66 children with refractive errors, 20(30.30\%) children were using spectacles, the rest were not aware of the presence of the problem, which could be due lack of awareness, attitudes regarding the need for spectacles, spectacle cost, cosmetic appearance. Out of refractive errors, $33.33 \%$ students had vision 6/9, 59.09\% students had vision $6 / 12,6.06 \%$ students had vision $6 / 18$ and $1.5 \%$ had vision $3 / 60$.
In the present study (5 to 12 years) prevalence of conjunctivitis was $2.64 \%$. Higher prevalence has been reported by Kumar R et al (2004) who observed $4.6 \%$ prevalence in urban and rural school children (5-14 yrs) of Delhi8. Trivedi et al (2006) observed $5.1 \%$ prevalence in children (7-15 yrs) of urban and rural areas of Gujarat9. Higher prevalence of conjunctivitis has been reported in other part of India10. In present study, no case of trachoma, bilateral blindness, $(\mathrm{VA}<3 / 60)$, vitamin A deficiency including bitot's spots have been reported.

The limitation of this study was that children less than 5 years of age were not included. Also, our study was school based, which may not reflect the clinical conditions in this community where a significant number of children may not attend school due to poverty.

\section{CONCLUSIONS}

The commonest cause of visual impairment in school students was refractive errors which can be prevented. Conjunctivitis was the second most common ocular disease which is also a treatable disease. Therefore, early detection, proper screening and evaluation of school students if done timely can help in reducing the burden of eye disease

\section{REFERENCES}

1. Gilbert C, Foster A. Childhood blindness in the context of VISION 2020 -the right to sight. Bull World Health Organ. 2001;79(3):227-32.

2. Taleb A, Ávila MP, Moreira H.As condições de saúde ocular no Brasil. São Paulo: Conselho Brasileiro de Oftalmologia; 2009.

3. Preventing Blindness in Children. Report of a WHO/IAPB Scientific Meeting, Hyderabad, India, 13-17 April 1999.

4. Deshpande JD, Malathi K. Prevalence of ocular morbidities among school children in rural area of North Maharashtra in India. Natl J Community Med 2011;2:302-4.

5. Pi LH, Chen L, Liu Q, Ke N, Fang J, Zhang $\mathrm{S}$, et al. Refractive status and prevalence of 
refractive errors in suburban school-age children. Int J Med Sci 2010;7:342-53.

6. Gaiotto PC, PassosJúnior W, Schellini AS, Shiratori CA, Padovani CR. [Ocularaffections in 2 to 8 year- old children at Piracicaba city - SP]. Medicina (RibeirãoPreto). 2002;35(4):487-91.

7. Dandona R, Dandona L. Refractive error blindness. Bull World Health Organ. 2001; 79:237-243.

8. Kumar R, Mehra M, Dobas P, Kamlesh, Raha R. A study of ocular infections amongst primary school children in Delhi. Indian J Commun Dis 2004; 36: 121- 26.

9. Trivedi V, Zalawadiya S, Bhatt JV, Pawar T, Kupmavat B. Prevalence of refractive errors in children of rural \& urban areas of Gujarat: A Population based study.

10. Khurana AK, Sikka KL, Parmar IPS, Aggarwal SK. Ocular morbidity among school children in Rohtak city. Indian J Public Health. 1984; 28:217-20. 